\title{
Effect of pre-endoscopy intake of simethicone solution on endoscopic mucosal visibility: A single blinded, placebo control, randomized trial
}

\author{
Bader Faiyaz Zuberi', Majid Ahmed Shaikh², \\ Faiza Sadaqat Ali ${ }^{3}$, Tazeen Rasheed ${ }^{4}$, Zunaira Nawaz ${ }^{5}$
}

\begin{abstract}
Objective: To determine effect of pre-endoscopy intake of simethicone solution on endoscopic mucosal visibility.

Methodology: A randomized, single blinded placebo control trial was done in patients undergoing oesophago-gastro-duodenoscopy for any indication at DOTs Endoscopy Suite, CHK during the period of April to June 2019. Informed consent was taken. Patients were randomly allocated in two groups. Group-A received placebo while Group-B received Simethicone. Evaluation of mucosal visibility was assessed at 4 sites (oesophagus, fundus, antrum \& duodenum) by previously validated scoring. Mean of visibility scores were compared in two groups.

Results: Two hundred and forty-eight patients were inducted and randomly allocate to two groups of 124 each. Mean of total sum of scores in Group-A was $8.14 \pm 2.44$ and that of Group-B was $5.80 \pm 1.75$ $(p<0.001)$. Adequate visibility in Group-A was seen in $41.1 \%$ and that in Group-B was $78.2 \%(p<0.001)$.

Conclusion: Use of Simethicone significantly improves mucosal visibility during OGD.
\end{abstract}

KEYWORDS: Endoscopy, Oesophago-gastro-duodenoscopy, Pre-medication, Simethicone.

doi: https://doi.org/10.12669/pjms.36.2.1241

How to cite this:

Zuberi BF, Shaikh MA, Ali FS, Rasheed T, Nawaz Z. Effect of pre-endoscopy intake of simethicone solution on endoscopic mucosal visibility: A single blinded, placebo control, randomized trial. Pak J Med Sci. 2020;36(2):172-176.

doi: https://doi.org/10.12669/pjms.36.2.1241

This is an Open Access article distributed under the terms of the Creative Commons Attribution License (http://creativecommons.org/licenses/by/3.0), which permits unrestricted use, distribution, and reproduction in any medium, provided the original work is properly cited.

\section{INTRODUCTION}

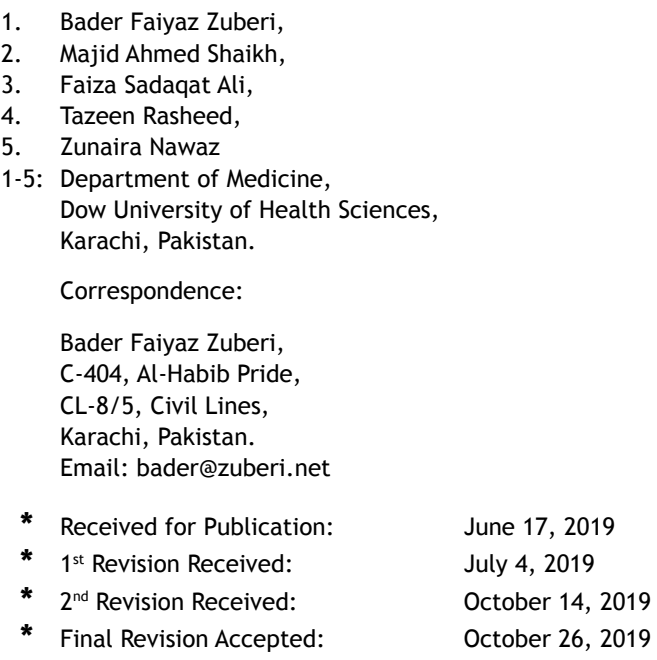

Oesophago-gastro-duodenoscopy (OGD) plays a crucial in diagnosis of upper GI disorders, and great importance lies in early detection of mucosal lesions for timely diagnosing and treating the hazardous diseases including malignancies. However, presence of intraluminal bubbles and foams hamper mucosal visibility, which may cause missing of subtle mucosal lesions ${ }^{1,2}$ and increasing operator's time of performing OGD. Simethicone (polydimethylsiloxane, plus silicon dioxide) is a tasteless, odorless, antifoaming agent which reduces surface tension, transforming small gas bubbles in larger ones which are easier to move and eliminate. ${ }^{3}$ It reduces gas related dyspeptic symptoms, and also has a gastroprotective effect. ${ }^{4}$ It is neither absorbed from gastrointestinal tract nor attached to other 
drugs, and rarely causes ant adverse effect, ${ }^{5}$ can be taken up to $900 \mathrm{mg} /$ day without any systemic toxicity. ${ }^{6}$

It has been reported that up to $13 \%$ of malignancies are missed in index OGD that are subsequently diagnosed in repeat procedure or other investigations. ${ }^{7,8}$ In presence of high definition endoscopic system, it is important that preparation should be extremely good to have proper visualization. Despite the effect of simethicone on mucosal visibility its use in OGD is not existent in practice. Neither there is any data on its use or efficacy from our region. There is dire need to establish its efficacy in OGD in a properly conducted trial.

This single blinded randomized control trial was carried out to evaluate the effect of Simethicone solution on mucosal visibility while performing OGD, with the intention of better diagnostic yield and formulating future guidelines for the use of Simethicone prior to OGD.

\section{METHODS}

All patients of ages 18-80 years undergoing endoscopy for any reason at DOTs Endoscopy Suite CHK, during the period of April-June 2019 were inducted into study after taking informed consent. Study was approved by Institutional Review Board of Dow University of Health Sciences, Karachi, Pakistan vide letter \# IRB-1242/DUHS/Approval/2019/57. Those having nasogastric tube insertion, stenosis of upper digestive tract, history of gastric surgery, active upper GI bleeding, cardiac and coronary artery diseases within six weeks, uncontrolled pulmonary diseases (with oxygen saturation of less than $90 \%$ at room air), pregnancy or breast feeding, thrombocytopenia (platelet less than $50,000 / \mathrm{mm}^{3}$ ), coagulopathy (INR over 1.4 ) and history of simethicone use within one week were excluded from study. Patients were selected using non-probability convenience sampling technique and consenting patients were randomly assigned into two groups using Random Allocation Software version 2.0. Group-A was given 50 $\mathrm{ml}$ of placebo while Group-B was given $15 \mathrm{ml}$ Simethicone (Infacol) syrup diluted in $35 \mathrm{ml}$ of water for ingestion 10 minutes before endoscopy (Fig.1). Endoscopist were blinded to the allocation status and were required to comment on mucosal visibility as per following scoring. ${ }^{9}$
Score 1: No foam and mucus on the mucosa.

Score 2: Little foam and mucus on the mucosa without obscuring vision.

Score 3: Large amount of foam and mucus on the mucosa, with less than $60 \mathrm{~mL}$ water to clear.

Score 4: Large amount of foam and mucus on the mucosa, with more than $60 \mathrm{~mL}$ water to clear.

Scoring was doneinfoursegmentsindependently, i.e., oesophagus, fundus, antrum \& duodenum. Data was collected and analysed using SPSS. Mean of scores in four segments were compared using Student's t-test. Scores of all four segments were summed up, the minimum possible score was four and maximum possible score was 16 . Total score of $\leq 7$ was taken as adequate visibility. Proportions of patients with acceptable visibility were compared in two groups by $x^{2}$-test. Significance level was set at $\leq 0.05$.

Sample size was calculated using previously reported visibility score of $65 \%$ and $44 \%$ in patients who received simethicone and those who did not. ${ }^{10}$ Calculation method used was test for two proportions using Z-test with power of $90 \%$ and alpha of 0.05 . Sample size was calculated as 234 with 117 patients in each group. Sample size was calculated using PASS 2019 software using formula: $\mathrm{n}=(\mathrm{Za} / 2+\mathrm{Z} \beta) 2 *(\mathrm{p} 1(1-\mathrm{p} 1)+\mathrm{p} 2(1-\mathrm{p} 2)) /(\mathrm{p} 1-\mathrm{p} 2) 2$ where $Z a / 2$ is the critical value of the Normal distribution at $\alpha / 2$ (e.g. for a confidence level of $95 \%, \alpha$ is 0.05 and the critical value is 1.96), $Z \beta$ is the critical value of the Normal distribution at $\beta$ (e.g. for

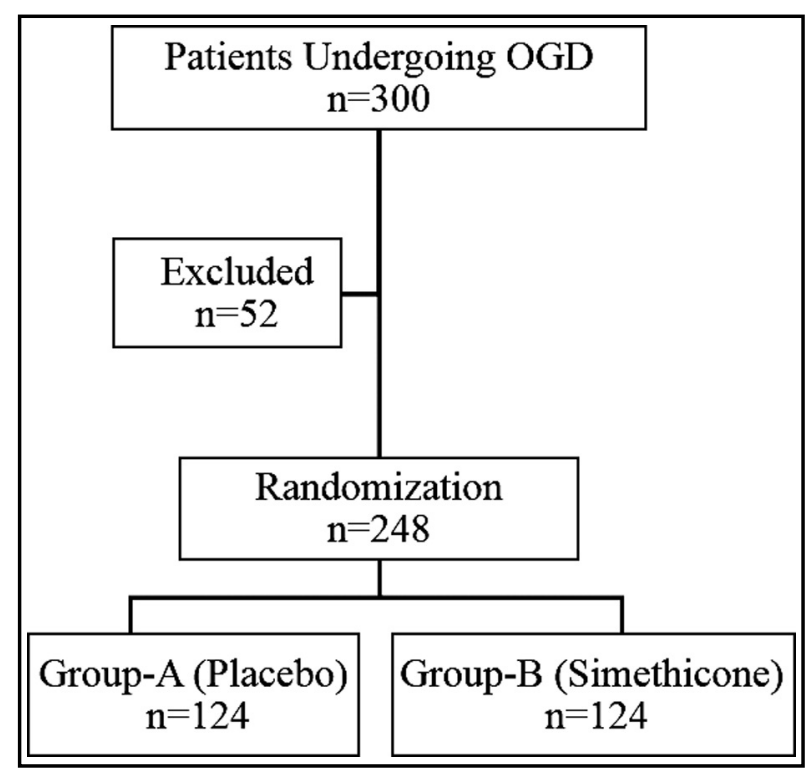

Fig.1: Randomization Protocol. 
Table-I: Demographic details of patients.

\begin{tabular}{lcccc}
\hline & \multicolumn{2}{c}{ Group-A } & \multicolumn{2}{c}{ Group-B } \\
\cline { 2 - 5 } & Male & Female & Male & Female \\
\hline $\mathrm{n}(\%)$ & $76(61.3 \%)$ & $48(38.7 \%)$ & $66(53.2 \%)$ & $58(46.8 \%)$ \\
Age mean \pm SD (years) & $35.96 \pm 9.0$ & $34.75 \pm 9.12$ & $46.91 \pm 14.73$ & $46.57 \pm 16.31$ \\
\hline
\end{tabular}

a power of $80 \%, \beta$ is 0.2 and the critical value is 0.84 ) and $\mathrm{p} 1$ and $\mathrm{p} 2$ are the expected sample proportions of the two groups.

\section{RESULTS}

Three hundred patients were initially selected for the trial, fifty-two were excluded for various reasons. Two hundred forty-eight patients fulfilling selection criteria were inducted and allocated to two groups of 124 each with randomization table created by Random Allocation Software. Group-A consisted of $76(61.3 \%)$ males and 48 (38.7\%) females. Group-B had 66 (53.2\%) males and 58 $(46.8 \%)$ females. Mean age \pm SD in Group-A of males was $35.96 \pm 9.0$ years while that of females was $34.75 \pm 9.12$ years. There was no significant difference in age between gender in Group-A $(p=0.47 ; \mathrm{df}=122 ; 95 \% \mathrm{CI}-2.09$ to 4.5$)$. Mean age $\pm S D$ in Group-B of males was $46.91 \pm 14.73$ years while that of females was $46.57 \pm 16.31$ years. There was no significant difference in age between gender in Group-B ( $p=0.903$; $\mathrm{df}=122 ; 95 \%$ CI -5.18 to 5.86 ). Details are given in Table-I.

Visibility Scores from different segments of upper GI tract showed no significant difference between both groups in oesophagus, but significantly better visibility scores were observed in Fundus, Antrum and Duodenum on statistical analysis using ANOVA. Details are given in Table-II.

The scores from four segments of GI tract were summed up. The means of the total sum score were compared among groups by Student's t-test that showed that mean score \pm SD of Group-A was $8.14 \pm 2.44$ and that of Group-B was $5.80 \pm 1.75(p$ $<0.001 ; \mathrm{df}=246 ; 95 \%$ CI 1.808 to 2.869 ). The analysis showed significantly better mucosal visualization in Group-B.

Variable of total score was recoded if the score was $\leq 7$ or $>7$ to see if the mucosal visibility score
Table-II: Mean visibility scores according to site and statistical analysis by ANOVA.

\begin{tabular}{llccc}
\hline & Group & Mean & $S D$ & p-value \\
\hline Oesophagus & Group-A & 1.39 & 0.489 & 0.108 \\
& Group-B & 1.29 & 0.456 & \\
Fundus & Group-A & 2.43 & 0.866 & $<0.001$ \\
& Group-B & 1.42 & 0.700 & \\
Antrum & Group-A & 2.70 & 0.954 & $<0.001$ \\
& Group-B & 1.63 & 0.749 & \\
Duodenum & Group-A & 1.62 & 0.694 & 0.037 \\
& Group-B & 1.46 & 0.500 & \\
Total Score & Group-A & 8.14 & 2.437 & $<0.001$ \\
& Group-B & 5.80 & 1.748 & \\
\hline
\end{tabular}

was adequate or not. The results showed that the adequate visibility in Group-A was seen in $51(41.1 \%)$ and that in Group-B was $97(78.2 \%)$. Statistical analysis using $\chi^{2}$ test showed that mucosal visibility was significantly better in Group-B $(p$ $<0.001)$, details in Table-III. No adverse effects due to simethicone were reported in our study.

\section{DISCUSSION}

This study demonstrates improved mucosal visualization on OGD after Simethicone. The effect is highly significant as shown by statistical analysis. This improvement was also shown by Elvas L et al. in a single blinded, placebo control study on the impact of simethicone on quality of reporting, significant improvement in mucosal visualization and detection of subtle lesions like dysplasia and small polyps and changes of Barrett's. ${ }^{11}$ They used three groups and used water in first group, simethicone in second and simethicone and N-acetyl cystine in the third group, where they showed significant improvement in mucosal visibility in those who received simethicone. ${ }^{11}$ Subtle findings are difficult to detect and could easily be missed in presence of mucous and foam. ${ }^{12}$ Similar results were also reported by Monrroy $\mathrm{H}$ et $a .^{10}$ This is

Table-III: Comparison of mean visibility scores and adequate visibility with statistical significance.

\begin{tabular}{lcccc}
\hline & Group-A & Group-B & P-Value & Statistical test used \\
\hline Mean Visibility Scores & $8.14 \pm 2.44$ & $5.80 \pm 1.75$ & $<0.001$ & Students t test \\
Adequate Visibility & $51(41.1 \%)$ & $97(78.2 \%)$ & $<0.001$ & Chi-square test \\
\hline
\end{tabular}


also reported that pre-procedure drink containing simethicone not only significantly improves mucosal visibility during OGD but also reduces the need for flushes during the procedure. ${ }^{13}$

In our study we did not come across any adverse effect in patients who received simethicone. This finding was similar to many other trials carried out to see the safety of pre-endoscopic use of simethicone. ${ }^{9}$ Despite these findings some centres do not advocate premedication before OGD due to several reasons; such as increase endoscopy schedule time; the worry of hypersensitivity reaction from medications ( $\mathrm{N}$-acetylcysteine); and the worry of aspiration from drinking larger amount of premedication just before OGD. As in Singapore where major proportion of population comprises of aging population, endoscopy is commonly carried out to assess swallowing dysfunction. ${ }^{14}$ They use $100 \mathrm{~mL}$ premedication solution along with moderate sedation before gastroscopy. This puts these patients at risk for aspiration, especially in patients with stroke. ${ }^{15}$ Main reasons of having no adverse effects in our study are possibly because we used very minimal amount of premedication ( $15 \mathrm{ml}$ of simethicone in $35 \mathrm{ml}$ water) and it was given 10 minutes before procedure, not just before the procedure. Hypersensitivity did not occur with simethicone which might be a fear if $\mathrm{N}$-acetylcystein were have been used as premedication.

Simethicone has also been found very helpful in small bowel preparation in capsule endoscopy and there are several studies to document this effect. ${ }^{16-18}$ Furthermore multicentre randomized control trial also highlighted that the use of simethicone along with low volume of large bowel preparation solution (Clensia) before colonoscopy resulted in better tolerability by patients and almost equal mucosal visibility by colonoscpist as compared to standard 4 liter PEG solution for large bowel preparation. ${ }^{19}$

To date, there is no international consensus on premedication use for upper gastrointestinal endoscopy. For example, Japanese endoscopists routinely use premedication to achieve better visibility of the gastric mucosa. Contrary to that, Bhandari $\mathrm{P}$, et al. in their study conducted in Japanese tertiary referral centre among 112 participants, did not recommend the routine use of mucosal clearing agents like Gascon and Pronase prior to or as targeted during gastroscopy, as they found no difference in endoscopic time, though they required fewer flushes during endoscopy. ${ }^{20}$ There is also no standard recommendation or guidelines for such practice in China.

As a result of the present study, we recommend the routine use of premedication with simethicone prior to OGD as it improved visibility of the mucosa and found safe. However, further studies are required to answer whether improving endoscopic visibility will result in increased detection of small but important lesions in the upper digestive tract.

Limitation of the study: It includes use of amount of water requiring for flushing to improve mucosal visualization is operator dependent and may not be considered as an adequate measuring tool. The development of a validated and an agreed scoring tool for mucosal visibility as well as consensus regarding dose and timing of simethicone is mandatory before running further trials to validate findings of current study and previously published trials. Comparison between Simethicone versus NAC, Pronase versus NAC and Pronase versus Simethicone and may also need to be explored before the routine use of Simethicone as premedication for OGD.

\section{CONCLUSION}

Use of Simethicone in patients undergoing OGD improves mucosal visibility during procedure and is safe. It should be recommended as standard procedure before OGD.

Conflict of Interest: All authors disclose no conflict of interest in this study

\section{REFERENCES}

1. Keeratichananont S, Sobhonslidsuk A, Kitiyakara $\mathrm{T}$, Achalanan N, Soonthornpun S. The role of liquid simethicone in enhancing endoscopic visibility prior to esophagogastroduodenoscopy (EGD): A prospective, randomized, double-blinded, placebo-controlled trial. J Med Assoc Thai. 2010;93(8):892-897.

2. Park JJ, Lee SK, Jang JY, Kim HJ, Kim NH. The effectiveness of simethicone in improving visibility during colonoscopy. Hepatogastroenterology 2009;56(94-95):1321-1325.

3. Surdea-Blaga T, Bancila I, Dobru D, Drug V, Fratila $\mathrm{O}$, Goldis A, et al. Mucosal Protective Compounds in the Treatment of Gastroesophageal Reflux Disease. A Position Paper Based on Evidence of the Romanian Society of Neurogastroenterology. J Gastrointestin Liver Dis. 2016;25(4):537-546. doi: 10.15403/ jgld.2014.1121.254.dea

4. Yeh JH, Hsu MH, Tseng CM, Chen TH, Huang RY, Lee $\mathrm{CT}$, et al. The benefit of adding oral simethicone in bowel preparation regimen for the detection of colon adenoma: A systematic review and meta-analysis. J Gastroenterol Hepatol. 2019;34(5):830-836. doi: 10.1111/jgh.14508 
5. Albert J, Göbel C-M, Leßke J, Lotterer E, Nietsch H, Fleig WE. Simethicone for small bowel preparation for capsule endoscopy: a systematic, single-blinded, controlled study. Gastrointest Endosc. 2004;59(4):487-491.

6. Szymczak CE, Walter JT. Simethicone solid oral dosage form. Google Patents. 2006.

7. Raftopoulos SC, Segarajasingam DS, Burke V, Ee HC, Yusoff IF. A cohort study of missed and new cancers after esophagogastroduodenoscopy. Am J Gastroenterol. 2010;105(6):1292-1297. doi: 10.1038/ajg.2009.736

8. Khalil Q, Gopalswamy N, Agrawal S. Missed esophageal and gastric cancers after esophagogastroduodenoscopy in a midwestern military veteran population. South Med J. 2014;107(4):225-228. doi: 10.1097/SMJ.0000000000000092

9. Zhang LY, Li WY, Ji M, Liu FK, Chen GY, Wu SS, et al. Efficacy and safety of using premedication with simethicone/Pronase during upper gastrointestinal endoscopy examination with sedation: A single center, prospective, single blinded, randomized controlled trial. Dig Endosc. 2018;30(1):57-64. doi: 10.1111/den.12952

10. Monrroy H, Vargas JI, Glasinovic E, Candia R, Azua E, Galvez C, et al. Use of N-acetylcysteine plus simethicone to improve mucosal visibility during upper GI endoscopy: a double-blind, randomized controlled trial. Gastrointest Endosc. 2018;87(4):986-993. doi: 10.1016/j.gie.2017.10.005

11. Elvas L, Areia M, Brito D, Alves S, Saraiva S, Cadime AT. Premedication with simethicone and $\mathrm{N}$-acetylcysteine in improving visibility during upper endoscopy: a doubleblind randomized trial. Endoscopy. 2017;49(2):139-145. doi: 10.1055/s-0042-119034

12. Spinzi G, Andrealli A, Conforti FS. Use of N-acetylcysteine plus simethicone to improve mucosal visibility during upper GI endoscopy. Gastrointest Endosc. 2018;88(3):575. doi: 10.1016/j.gie.2018.04.2348

13. Basford PJ, Brown J, Gadeke L, Fogg C, HaysomNewport B, Ogollah R, et al. A randomized controlled trial of pre-procedure simethicone and $\mathrm{N}$-acetylcysteine to improve mucosal visibility during gastroscopy NICEVIS. Endosc Int Open. 2016;4(11):E1197-E1202. doi: 10.1055/s-0042-117631

14. Yap MT, Gee C. Ageing in Singapore: social issues and policy challenges. 50 years of social issues in Singapore: World Scientific 2015:3-30. doi: 10.1142/9789814632621_0001
15. Osawa A, Maeshima S, Tanahashi N. Water-swallowing test: screening for aspiration in stroke patients. Cerebrovasc Dis. 2013;35(3):276-281. doi: 10.1159/000348683

16. Wu L, Cao Y, Liao C, Huang J, Gao F. Systematic review and meta-analysis of randomized controlled trials of Simethicone for gastrointestinal endoscopic visibility. Scand J Gastroenterol. 2011;46(2):227-235. doi: 10.3109/00365521.2010.525714

17. Krijbolder MS, Grooteman KV, Bogers SK, de Jong DJ. Addition of simethicone improves small bowel capsule endoscopy visualisation quality. Neth J Med. 2018;76(1):27-31.

18. Papamichael K, Karatzas P, Theodoropoulos I, Kyriakos N, Archavlis E, Mantzaris GJ. Simethicone adjunct to polyethylene glycol improves small bowel capsule endoscopy imaging in non-Crohn's disease patients. Ann Gastroenterol. 2015;28(4):464-468.

19. Spada C, Cesaro P, Bazzoli F, Saracco GM, Cipolletta L, Buri L, et al. Evaluation of Clensia((R)), a new low-volume PEG bowel preparation in colonoscopy: Multicentre randomized controlled trial versus 4L PEG. Dig Liver Dis. 2017;49(6):651656. doi: 10.1016/j.dld.2017.01.167

20. Bhandari P, Green S, Hamanaka H, Nakajima T, Matsuda T, Saito Y, et al. Use of Gascon and Pronase either as a pre-endoscopic drink or as targeted endoscopic flushes to improve visibility during gastroscopy: a prospective, randomized, controlled, blinded trial. Scand J Gastroenterol. 2010;45(3):357-361. doi: 10.3109/00365520903483643

\section{Author`s Contribution:}

BFZ: Conceived the study and gave final approval of manuscript, is responsible for integrity of research. MAS: Did data collection and analysis.

TZ: Drafted the article.

FSA: Did critical revision for important intellectual content.

ZN: Did statistical analysis and collected study data. 